\title{
Effects of alpha-tocopherol on fracture resistance after endodontic treatment, bleaching and restoration
}

\author{
Keren Cristina Fagundes \\ JORDÃO-BASSO(a) \\ Milton Carlos KUGA(a) \\ Andrea Abi Rached DANTAS ${ }^{(a)}$ \\ Mateus Rodrigues TONETTO ${ }^{(b)}$ \\ Suellen Nogueira Linhares LIMA(c) \\ Matheus Coêlho BANDÉCA ${ }^{(c)}$ \\ (a) Universidade Estadual Paulista - UNESP, \\ Araraquara Dental School, Department of \\ Restorative, Araraquara, SP, Brazil. \\ (b) Universidade de Cuiabá - UNIC, \\ Department of Dentistry, Cuiabá, MT, Brazil. \\ (c) Universidade CEUMA - UNICEUMA, \\ Department of Dentistry, São Luis, MA, Brazil.
}

Declaration of Interests: The authors certify that they have no commercial or associative interest that represents a conflict of interest in connection with the manuscript.

\section{Corresponding Author:}

Matheus Coelho Bandeca

E-mail: mbandeca@gmail.com

DOI: 10.1590/1807-3107BOR-2016.vol30.0069

Submitted: Dec 17, 2015

Accepted for publication: Mar 06, 2016

Last revision: Apr 04, 2016

\begin{abstract}
This study evaluated the effects of $10 \%$ alphatocopherol on the fracture resistance of endodontically treated teeth subjected to tooth bleaching with hydrogen peroxide and immediately restored with composite resin. Fifty bovine incisors were selected, including 10 sound teeth that constituted the control group (G1 (C)). The remaining 40 teeth, which were endodontically treated, were divided into four groups $(\mathrm{n}=10)$ : $\mathrm{G} 2(\mathrm{CR})$, consisting of teeth immediately restored with composite resin; G3 $(\mathrm{HP}+\mathrm{CR})$, consisting of teeth subjected to tooth bleaching with $38 \%$ hydrogen peroxide and immediately restored with composite resin; G4 (HP + SA + CR), which received treatment similar to that used for G3, but with 10\% sodium ascorbate gel applied after the bleaching protocol; and G5 (HP + AT + CR), which was similar to G4 but included 10\% alphatocopherol gel as an antioxidant. After $24 \mathrm{~h}$, composite restorations were performed, and teeth were subjected to a fracture resistance test at a speed of $0.5 \mathrm{~mm} / \mathrm{min}$ in an electromechanical testing machine. The axial force was applied with an angle of incidence of $135^{\circ}$ relative to the long axis of the root. Data were subjected to ANOVA and Tukey tests $(p=0.05)$. G1 exhibited the highest fracture resistance $(p<0.05)$. No significant differences among the other experimental groups were observed. The $10 \%$ sodium ascorbate and $10 \%$ alphatocopherol gels did not improve the fracture resistance of endodontically treated teeth subjected to bleaching with $38 \%$ hydrogen peroxide.
\end{abstract}

Keywords: Antioxidants; Tooth Bleaching; Endodontics.

\section{Introduction}

Tooth bleaching is based on complex oxidation reactions involving the release of singlet oxygen, hydroxyl and perhydroxyl ions. ${ }^{1}$ At times, clinical strategies require tooth bleaching followed by restoration with composite resin during a single session. ${ }^{2}$

Hydrogen peroxide is a bleaching agent used at concentrations ranging from $5 \%$ to $40 \%$. Higher concentrations are caustic, aggressively affect oral tissues, release free radicals and deleteriously affect dental structure. ${ }^{3,4}$ Peroxide readily diffuses because of its low molecular weight, and singlet oxygen is released within dentin tubules during the bleaching process. ${ }^{1}$ These free radicals tend to persist for a time within dentin tubules and 
adversely interfere with the penetration of adhesive monomers into dentin, thereby hampering hybrid layer formation. $5,6,7,8,9$

Moreover, these free radicals combine with hydroxyapatite and produce apatite peroxide.,10 which degrades phosphate and calcium and thus reduces the fracture resistance of the dental crown. ${ }^{10,11}$ In addition, after bleaching, the strengths of the adhesive system's bonds to dentin and enamel are reduced due to changes in surface roughness, increases in enamel porosity, reductions in microhardness, and changes in the mechanical properties of enamel and dentin., ${ }^{4,12,13}$

To minimize these undesirable effects, the use of antioxidants to neutralize free radicals before the final restoration is recommended; this process improves bond strength and restoration longevity, particularly in cases when restoration must be immediately performed. ${ }^{14}$

Ascorbic acid and one of its derivatives, sodium ascorbate, are the most commonly used antioxidants in dentistry. $7,15,16,17,18,19,20$ However, the use of ascorbic acid during bleaching procedures is not recommended because of its acidity and the risk of dental crown discoloration. ${ }^{21}$ In contrast, $10 \%$ sodium ascorbate solution can effectively neutralize singlet oxygen and other products on the dentin surface. This solution can improve the adhesion and bond strength of the adhesive system, thereby preventing adhesive failure and reversing reductions in the fracture resistance of endodontically treated teeth subjected to tooth bleaching. However, sodium ascorbate also causes tooth discoloration. ${ }^{8,14,15,18,22}$

Alphatocopherol, the most active component of vitamin $\mathrm{E}$, is a promising alternative antioxidant because it does not cause tooth discoloration. Sasaki et al. ${ }^{21}$ have observed that this antioxidant reverses changes in the strength of the adhesive system's bonds to dentin after tooth bleaching. However, the effects of this antioxidant on the fracture resistance of endodontically treated teeth after bleaching remain unknown.

Thus, the aim of this study was to evaluate the effects of alphatocopherol on the fracture resistance of endodontically treated teeth subjected to tooth bleaching with $38 \%$ hydrogen peroxide and immediately restored using a total-etching adhesive system and composite resin.

\section{Methodology}

Fifty bovine incisors with dental crowns of similar dimensions with respect to height and width (with a maximum variation of $\pm 1.0 \mathrm{~mm}$ ) were selected for the study, radiographically evaluated and stored in thymol solution $(0.1 \% ; \mathrm{pH} 7.0)$ at $4^{\circ} \mathrm{C}$. After $24 \mathrm{~h}$ of immersion in distilled water to remove thymol residues, the teeth were examined with a stereomicroscope (Leica Microsystems, Biberach, Germany) at a magnification of 20x; specimens with cracks or anatomical anomalies were discarded and replaced.

The roots of all specimens were included in a plastic matrix (16.5 mm internal width $\times 20.0 \mathrm{~mm}$ length), embedded in polyester resin (Maxi Rubber, São Paulo, Brazil) placed $2.0 \mathrm{~mm}$ below the cemento-enamel junction and allowed to rest for 24 hours until the resin polymerization was complete. Ten sound teeth were used as the control group (G1 (C)); these teeth received no treatment.

Pulp chamber access was achieved with a 1014 spherical diamond drill (KG Sorensen, Cotia, Brazil), and the access diameter was standardized with a \#12 steel spherical bur. Root canals were performed with the crown-down technique, ${ }^{11}$ using K-files up to \#80 (Mailefer, Ballaigues, Switzerland), and irrigated with $2.5 \%$ sodium hypochlorite after each file change. After biomechanical preparation, the root canals were irrigated with $3 \mathrm{~mL}$ of 17\% EDTA (Biodinâmica, Ibiporã, Brazil) for 3 minutes.

The root canals were irrigated with $10 \mathrm{~mL}$ of distilled water and dried with absorbent paper points (Dentsply-Herpo, Petrópolis, Brazil). These canals were then obturated using gutta-percha (Dentsply Ind. Com. Ltda., Petrópolis, Brazil) and an epoxy-based sealer (AH Plus; Dentsply De Trey, Konstanz, Germany); the active lateral condensation technique was performed..$^{23}$ Radiographs were obtained to evaluate obturation quality.

A heated plugger was used to remove $3 \mathrm{~mm}$ of gutta percha from the root canal, and a cervical barrier with a self-curing glass ionomer (Maxxion R A3; FGM Produtos Odontológicos Ltda., Joinville, 
Brazil) was placed up to the cemento-enamel junction. Cavity access was restored with provisional restorative cement (IRM; Dentsply Ind. Com. Ltda., Petrópolis, Brazil), and the teeth were immediately immersed in artificial saliva (Faculdade de Ciências Farmacêuticas de Ribeirão Preto, Universidade de São Paulo - USP, Ribeirão Preto, SP, Brazil).

After $24 \mathrm{~h}$, the provisional restoration was removed, and the pulp chamber was irrigated with $2.5 \mathrm{~mL}$ of $2.5 \%$ sodium hypochlorite and $2.5 \mathrm{~mL}$ of distilled water. Dentin etching was performed for 15 seconds using 37\% phosphoric acid (Condac 37; FGM Produtos Odontológicos Ltda., Joinville, Brazil), and $60 \mathrm{~s}$ of distilled water was used to remove the acid. ${ }^{11}$ Teeth were randomly divided into four groups, according to the protocol applied $(\mathrm{n}=10)$.

For G2 (CR), specimens were etched, the adhesive system (Scotchbond Multi-Purpose; 3M ESPE, St. Paul, USA) was applied, and the dental crowns were restored with composite resin (Filtek Z-250; 3M, St. Paul, USA). The primer from the adhesive system was applied to the dentin using a brush tip (KG Sorensen, São Paulo, Brazil) and gently dried for 5 seconds. The dentin adhesive was then applied to the primed dentin and light-cured with an LED-laser system (LED Bluephase; Ivoclar Vivadent, Schan, Liechtenstein) at an intensity of $1,200 \mathrm{~mW} / \mathrm{cm}^{2}$ for 10 seconds. Subsequently, the pulp chamber was restored using composite resin in increments with thicknesses of $2 \mathrm{~mm}$ that were each light-cured for 40 seconds. ${ }^{24}$

For G3 (HP+CR), external and internal surfaces were subjected to bleaching with $38 \%$ hydrogen peroxide (Opalescence Xtra Boost; Ultradent Products Inc., South Jordan, USA). The bleaching gel was handled in accordance with the manufacturer's recommendations and applied to the tooth's buccal surface and within the pulp chamber at a thickness of approximately 2.0 millimeters. The gel remained on the buccal surface for $15 \mathrm{~min}$ and in the pulp chamber for $10 \mathrm{~min}$ and was then aspirated and reapplied twice under conditions similar to those described above. Subsequently, the gel was aspirated; the dental crown was then copiously rinsed with a gentle spray of water for
$1 \mathrm{~min}$, dried and immediately restored in a manner similar to the treatment used for G2. ${ }^{2}$

For G4 (HP + SA + CR), after a bleaching protocol similar to that used for G3 was used, 10\% sodium ascorbate gel (Apothicário, Araçatuba, Brazil) was applied to the buccal surface for $15 \mathrm{~min}$ and within the pulp chamber for 10 minutes. Subsequently, the tooth was rinsed with a gentle spray of water for $15 \mathrm{~s}$ and then immediately restored with a procedure similar to that used for $\mathrm{G} 2$. Similar procedures were performed for G5 (HP + AT + CR), although 10\% alphatocopherol antioxidant gel (Apothicário, Araçatuba, Brazil) was used instead of $10 \%$ sodium ascorbate gel.

After cavity access was restored, specimens were stored in artificial saliva for $24 \mathrm{~h}$ at $37^{\circ} \mathrm{C}$. The specimens were then placed in a fixed device and subjected to a fracture resistance test with a $5 \mathrm{kN}$ load cell at a speed of $0.5 \mathrm{~mm} / \mathrm{min}$ in an electromechanical testing machine (EMIC DL 2000; São José dos Pinhais, Brazil). An axial force with an angle of incidence of $135^{\circ}$ relative to the long axis of the root was applied. ${ }^{11}$ The last force applied before the crown fracture of the bovine tooth was determined. Data were statistically analyzed with a one-way ANOVA followed by a Tukey's test; a significance threshold of 0.05 was used.

\section{Results}

Table presents the means, standard deviations, and maximum and minimum values $(\mathrm{kN})$ of the forces required to fracture the dental crowns for each group. Significantly greater force $(1.58 \pm 0.29 \mathrm{kN})$ was required for dental crown fracture for G1 relative to the other experimental groups $(\mathrm{p}<0.05)$. No significant differences among the experimental groups G2 $(1.07 \pm 0.34 \mathrm{kN})$, G3 $(0.99 \pm 0.20 \mathrm{kN})$, G4 $(1.05 \pm 0.24 \mathrm{kN})$ and G5 $(1.04 \pm 0.11 \mathrm{kN})$ were observed, regardless of the bleaching and antioxidant (i.e., sodium ascorbate or alphatocopherol) protocols that were used $(p>0.05)$.

\section{Discussion}

The 10\% alphatocopherol gel did not improve the fracture resistances of endodontically treated teeth subjected to tooth bleaching with 38\% hydrogen peroxide and immediately restored with a 
Table. Means, standard deviations (DP), and maximum and minimum values $(k N)$ for dental crown fractures.

\begin{tabular}{lccccc}
\hline Variable & G1 & G2 & G3 & G4 & G5 \\
Mean (SD) & $1.58(0.29)^{\mathrm{a}}$ & $1.07(0.34)^{\mathrm{b}}$ & $0.99(0.20)^{\mathrm{b}}$ & $1.05(0.24)$ & $1.04(0.11)^{\mathrm{b}}$ \\
Max-Min & $2.08-1.07$ & $1.52-0.55$ & $1.36-0.69$ & $1.40-0.67$ & $1.19-0.80$ \\
\hline
\end{tabular}

Different letters indicate statistically significant differences ( $<$ 0.05). SD: standard deviation; Max: maximum; Min: minimum; $G 1$ (C): sound crowns; G2 (CR): restored crowns; G3 (HP+CR): bleached and immediately restored crowns; G4 (HP+SA+CR): bleached crowns subjected to sodium ascorbate application and restoration; and G5 (HP+AT+CR): bleached crowns subjected to alphatocopherol application and restoration.

total-etching adhesive system involving 3 steps and a composite resin. Instead, the alphatocopherol group exhibited fracture resistances similar to those of the other groups.

The catalysis of hydrogen peroxide releases free radicals that combine with hydroxyapatite and produce apatite peroxide, which degrades calcium and phosphate in the dental structure..$^{25}$ Antioxidants such as sodium ascorbate and alphatocopherol can partially reverse these negative effects of tooth bleaching. ${ }^{14,17,21}$

However, the application of $10 \%$ sodium ascorbate and alphatocopherol gels to endodontically treated teeth for $15 \mathrm{~min}$ after bleaching and restoration did not produce any effects, although the protocols were conducted in accordance with Lai et al., ${ }^{26}$ who have recommended application of the antioxidant for at least one-third of the bleaching treatment period.

In contrast, Khoroushi et al. ${ }^{14}$ have observed that $10 \%$ sodium ascorbate can reverse the negative effects of bleaching on dental crown fracture resistance. These negative effects occur when the dental structure is constantly exposed to peroxides in "in office" and "at home" treatments. The $38 \%$ peroxide hydrogen was applied 3 consecutive times for a total of $45 \mathrm{~min}$; the findings demonstrate that the beneficial effects of antioxidants may be related to prolonged periods of exposure to peroxides. ${ }^{27}$

The use of $10 \%$ alphatocopherol gel was based on the recommended concentration of sodium ascorbate that produces effective results. ${ }^{14}$ However, no studies have evaluated the ideal alphatocopherol concentration for use after bleaching; therefore, this $10 \%$ concentration may have been insufficient. Sasaki et al. ${ }^{21}$ have demonstrated that $10 \%$ alphatocopherol reverses the negative effects of carbamide peroxide on the strength of the bonds between a total-etching adhesive system and dentin.

Restorations using the total-etching adhesive system and composite resin influence the experimental groups, which exhibit similar results distinct from those obtained for sound teeth. ${ }^{11,28}$ Pobbe et al. ${ }^{29}$ have observed a significant reduction in the fracture resistances of dental crowns subjected to $38 \%$ hydrogen peroxide and light-curing with an LED-laser system after several treatment sessions. The photoactivation and repeated treatment sessions negatively affect the fracture resistance of the dental crown. ${ }^{30,31}$

In the fracture resistance assessment, a force was applied with an angle of incidence of $135^{\circ}$ relative to the long axis of the root to simulate natural conditions. ${ }^{2,11}$ Praddep et al. ${ }^{32}$ have observed that the fracture resistance of teeth bleached with peroxides is similar to that of sound teeth when an axial force is applied. However, this angle of incidence is not consistent with clinical conditions for upper incisors.

In contrast to $10 \%$ sodium ascorbate, $10 \%$ alphatocopherol does not induce tooth discoloration; ${ }^{21}$ however, in our study, the alphatocopherol gel neither reversed decreases in fracture resistance after the bleaching protocol and immediate restoration nor restored the strength of bonds between the adhesive system and dentin. ${ }^{33,34}$

It must be emphasized that a cement containing eugenol was used as a provisional restoration material between treatment sessions. Latta et al. ${ }^{35}$ have demonstrated that the use of phosphoric acid to clean the tooth surface is not beneficial. It is possible that the hybridization of the adhesive system to dentin was compromised and that this 
phenomenon contributed to the similarity of results among the experimental groups.

Further studies should be conducted to identify the ideal concentration and recommended conditions for alphatocopherol antioxidant application after bleaching with hydrogen peroxide.

\section{References}

1. Plotino G, Buono L, Grande NM, Pameijer CH, Somma F. Nonvital tooth bleaching: a review of the literature and clinical procedures. J Endod. 2008;34(4):394-407. doi:10.1016/j.joen.2007.12.020

2. Leonardo RT, Kuga MC, Guiotti FA, Andolfatto C, Faria-Júnior NB, Campos EA, et al. Fracture resistance of teeth submitted to several internal bleaching protocols. J Contemp Dent Pract. 2014;15(2):186-9. doi:10.5005/jp-journals-10024-1512

3. Chng HK, Palamara JE, Messer HH. Effect of hydrogen peroxide and sodium perborate on biomechanical properties of human dentin. J Endod. 2002;28(2):62-7. doi:10.1097/00004770-200202000-00003

4. Oliveira DP, Teixeira ECN, Ferraz CCR, Teixeira FB. Effect of intracoronal bleaching agents on dentin microhardness. J Endod. 2007;33(4):460-2. doi:10.1016/j.joen.2006.08.008

5. Titley KC, Torneck CD, Smith DC, Chernecky R, Adibfar A. Scanning electron microscopy observations on the penetration and structure of resin tags in bleached and unbleached bovine enamel. J Endod. 1991;17(2):72-5. doi:10.1016/S0099-2399(06)81611-0

6. Dishman MV, Covey DA, Baughan LW. The effects of peroxide bleaching on composite to enamel bond strength. Dent Mater. 1994;10(1):33-6. doi:10.1016/0109-5641(94)90019-1

7. Khoroushi M, Saneie T. Post-bleaching application of an antioxidant on dentin bond strength of three dental adhesives. Dent Res J (Isfahan). 2012;9(1):46-53. doi:10.4103/1735-3327.92943

8. Türkün M, Celik EU, Kaya AD, Arici M. Can the hydrogel form of sodium ascorbate be used to reverse compromised bond strength after bleaching? J Adhes Dent. 2009;11(1):35-40.

9. Moosavi H, Moghaddas MJ, Ghoddusi J, Rajabi O. Effects of two antioxidants on the microleakage of resin-based composite restorations after nonvital bleaching. J Contemp Dent Pract. 2010;11(6):E033-40.

10. Attin T, Paqué F, Ajam F, Lennon AM. Review of the current status of tooth whitening with the walking bleach technique. Int Endod J. 2003;36(5):313-29. doi:10.1046/j.1365-2591.2003.00667.x

11. Kuga MC, Reis JMSN, Fabrício S, Bonetti-Filho I, Campos EA, Faria G. Fracture strength of incisor

\section{Conclusion}

The $10 \%$ alphatocopherol had no significant effects on fracture resistance after bleaching with $38 \%$ hydrogen peroxide and immediate restoration with a total-etching adhesive system and composite resin.

crowns after intracoronal bleaching with sodium percarbonate. Dent Traumatol. 2012;28(3):238-42. doi:10.1111/j.1600-9657.2011.01077.x

12. Basting RT, Rodrigues JA, Serra MC, Pimenta LA. Shear bond strength of enamel treated with seven carbamide peroxide bleaching agents. J Esthet Restor Dent. 2004;16(4):250-9. doi:10.1111/j.1708-8240.2004.tb00046.x

13. Goldberg M, Grootveld M, Lynch E. Undesirable and adverse effects of tooth-whitening products: a review. Clin Oral Investig. 2010;14(1):1-10. doi:10.1007/s00784-009-0302-4

14. Khoroushi M, Feiz A, Khodamoradi R. Fracture resistance of endodontically-treated teeth: effect of combination bleaching and an antioxidant. Oper Dent. 2010;35(5):530-7. doi:10.2341/10-047-L

15. Lai SC, Mak YF, Cheung GS, Osorio R, Toledano M, Carvalho RM, et al. Reversal of compromised bonding to oxidized etched dentin. J Dent Res. 2001;80(10):1919-24. doi:10.1177/00220345010800101101

16. Türkün M, Kaya AD. Effect of $10 \%$ sodium ascorbate on the shear bond strength of composite resin to bleached bovine enamel. J Oral Rehabil. 2004;31(12):1184-91. doi:10.1111/j.1365-2842.2004.01369.x

17. Kimyai S, Valizadeh H. The effect of hydrogel and solution of sodium ascorbate on bond strength in bleached enamel. Oper Dent. 2006;31(4):496-9. doi:10.2341/05-85

18. Kimyai S, Valizadeh H. Comparison of the effect of hydrogel and a solution of sodium ascorbate on dentin-composite bond strength after bleaching. J Contemp Dent Pract. 2008;9(2):105-12.

19. Gökçe B, Cömlekoğlu ME, Ozpinar B, Türkün M, Kaya AD. Effect of antioxidant treatment on bond strength of a luting resin to bleached enamel. J Dent. 2008;36(10):780-5. doi:10.1016/j.jdent.2008.05.008

20. Freire A, Souza EM, Caldas DBM, Rosa EAR, Bordin CFW, Carvalho RM, et al. Reaction kinetics of sodium ascorbate and dental bleaching gel. J Dent. 2009;37(12):932-6. doi:10.1016/j.jdent.2009.07.008

21. Sasaki RT, Flório FM, Basting RT. Effect of $10 \%$ sodium ascorbate and $10 \%$ alpha-tocopherol in different formulations on the shear bond strength of enamel and dentin submitted to a home-use bleaching treatment. Oper Dent. 2009;34(6):746-52. doi:10.2341/09-029-L 
22. Kaya AD, Türkün M. Reversal of dentin bonding to bleached teeth. Oper Dent 2003;28(6):825-9.

23. Magro MG, Kuga MC, Aranda-Garcia AJ, Victorino KR, Chávez-Andrade GM, Faria G, et al. Effectiveness of several solutions to prevent the formation of precipitate due to the interaction between sodium hypochlorite and chlorhexidine and its effect on bond strength of an epoxy-based sealer. Int Endod J. 2015;48(5):478-83. doi:10.1111/iej.12337

24. Piccioni MARV, Baratto-Filho F, Kuga MC, Morais ECC, Campos EA. Cuspal movement related to different polymerization protocols. J Contemp Dent Pract. 2014;15(1):26-8. doi:10.5005/jp-journals-10024-1482

25. Zhao H, Li X, Wang J, Qu S, Weng J, Zhang X. Characterization of peroxide ions in hydroxyapatite lattice. J Biomed Mater Res. 2000;52(1):157-63. doi:10.1002/1097-4636(200010)52:1<157::AID-JBM20>3.0.CO;2-U

26. Lai SC, Tay FR, Cheung GS, Mak YF, Carvalho RM, Wei SH, et al. Reversal of compromised bonding in bleached enamel. J Dent Res. 2002;81(7):477-81. doi:10.1177/154405910208100709

27. Woo JM, Ho S, Tam LE. The effect of bleaching time on dentin fracture toughness in vitro. J Esthet Restor Dent. 2010;22(3):179-84. doi:10.1111/j.1708-8240.2010.00333.x

28. Roberto AR, Sousa-Neto MD, Viapiana R, Giovani AR, Souza- Filho CB, Paulino SM, et al. Effect of different restorative procedures on the fracture resistance of teeth submitted to internal bleaching. Braz Oral Res. 2012. ;26(1):77-82. doi:10.1590/S1806-83242012000100013
29. Pobbe PO, Viapiana R, Souza-Gabriel AE, Marchesan MA Sousa-Neto MD, Silva-Sousa YT, et al. Coronal resistance to fracture of endodontically treated teeth submitted to light-activated bleaching. J Dent. 2008;36(11):935-9. doi:10.1016/j.jdent.2008.07.007

30. Turssi CP, Schiavoni RJ, Serra MC, Froner IC. Permeability of enamel following light-activated power bleaching. Gen Dent. 2006;54(5):323-6.

31. Araujo FO, Baratieri LN, Araújo E. In situ study of in-office bleaching procedures using light sources on human enamel microhardness. Oper Dent. 2010;35(2):139-46. doi:10.2341/08-033-C

32. Pradeep P, Kumar VS, Bantwal SR, Gulati GS. Fracture strength of endodontically treated premolars: an in-vitro evaluation. J Int Oral Health. 2013;5(6):9-17.

33. Whang HJ, Shin DH. Effects of applying antioxidants on bond strength of bleached bovine dentin. Restor Dent Endod. 2015;40(1):37-43. doi:10.5395/rde.2015.40.1.37

34. Thapa A, Vivekananda PA, Thomas MS. Evaluation and comparison of bond strength to $10 \%$ carbamide peroxide bleached enamel following the application of $10 \%$ and $25 \%$ sodium ascorbate and alpha-tocopherol solutions: an in vitro study. J Conserv Dent. 2013;16(2):111-5. doi:10.4103/0972-0707.108184

35. Latta MA, Kelsey WP, Murdock CM. Effects of adhesive liner and provisional cement on the bond strength of nickel/chrome/beryllium alloy cemented to dentin. Quintessence Int. 2005;36(10):817-23. 